\title{
A Conversational Analysis Model for Promoting Practices of Interactional Competence in the EFL Context
}

\author{
Sami Ali Nasr Al-wossabi ${ }^{1}$ \\ ${ }^{1}$ English Department, Faculty of Arts and Humanities, Jazan University, Jazan, Saudi Arabia \\ Correspondence: Sami Ali Nasr Al-wossabi, English Department, Faculty of Arts and Humanities, Jazan \\ University, Jazan, Saudi Arabia. E-mail: sami_ed@hotmail.com
}

$\begin{aligned} & \text { Received: September 1, } 2016 \\ & \text { Accepted: September 26, } 2016 \quad \text { Online Published: November 23, } 2016 \\ & \text { doi:10.5539/ijel.v6n6p32 }\end{aligned}$ URL: http://dx.doi.org/10.5539/ijel.v6n6p32

\begin{abstract}
Formulaic language is a typical feature of textbooks materials used in EFL classes. EFL students are not engaged in the process of recognizing how naturally occurring speech takes place and is carried on. EFL learners in their helpless attempts to converse with others may tend to memorize formulaic fixed expressions and sometimes whole conversations. Following a conversation analysis approach, the present study explores the significance of involving Saudi EFL learners in understanding the flow and structure of spontaneous and interactive conversation. A sample of an excerpt taken from a conversation of an American TV talk show was recorded and transcribed. Practices of interactional competence such as conversational organization, situational characteristics, lexical choices, linguistics devices, and other conventions of speech behavior are identified and then discussed in details. This CA approach is, therefore, meant to serve as a model of salient interactive practices and norms that present the conversational system of actual everyday talk. The purpose is to raise EFL learners' awareness of the socio-cultural features of real-world communication and enhance their interactional skills necessary to boost their communicative competencies.
\end{abstract}

Keywords: conversational analysis, interactional competence, conversational organization, linguistic devices

\section{Introduction}

New ESL textbooks are said to integrate competencies and communicative objectives addressing the students' need to properly use the language. Yet, the claims and intentions stated by these textbooks cannot be clearly noticed and realized when used in an EFL context. Walsh (2012) suggested that

Although contemporary materials claim to adopt a task-based approach to teaching and learning, they do not, I suggest, train learners to become better interactants. All attention is directed towards the individual's ability to produce accurate, appropriate and fluent utterances. (p. 2)

In fact, as Jaen \& Basanta (2009) pointed out, "textbook conversations use artificial scripted dialogues based on someone's intuitions about what people are likely to say or in most cases drawn from written language" (p. 287). Many researches, in particular those of corpus based nature, tackle the issue of the necessity of including linguistic aspects of conversational grammar in L2 textbooks, claiming that EFL/ESL textbooks do not correspond to the natural occurring speech (Gilmore, 2004; Biber \& Reppen, 2002; Barbieri \& Eckhardt, 2007).

In such artificial and limited L2 environment, learners view conversations as static process rather than active and dynamic process of discourse construction. EFL learners are indeed in great need to understand that "conversation is a social process governed by particular historical rules that govern what canbe and cannot be said and who can speak and who must listen" (Kincheloe, 2005, p. 122).

The present study proposes that raising awareness of the mechanisms of conversational analysis in the EFL settings could virtually compensate for such shortcomings in the teaching of oral skills. Such mechanisms, though critical, are missing components in the EFL classrooms even where the CLT approach is supposed to be used. The language that learners are exposed to is rigid and don't characterize the linguistic or socio-cultural practices embedded in actual talk of everyday English.

Applying CA in the Saudi EFL speaking classes could boost the recognition and use of naturally occurring practices and norms of speech behaviors used by native speakers of English. It could rather enliven and update traditional communicative practices used for many years in such contexts with no tangible effects on most 
learners' output.

Many SLA studies, as it will be shown in the next sections, have deeply reflected on the effects of using CA approach for better L2 acquisition. Such studies have tackled the analysis of conversations of students- teachers' talk and also the native speakers' talk. The aim is to uncover the linguistic, pragmatic and organizational conventions that form naturally occurring discourse. These interactional conventions and practices are believed to contribute to better L2 acquisition as well production. The present paper is of the same opinion. However, it only advocates the analysis of naturally occurring discourse excerpts to be used in EFL speaking classes. The reason behind such advocacy is to engage learners in the pragmatic, authentic, and functional use of language for meaningful purposes.

\section{Literature Review}

\subsection{Conversation Analysis}

Biber et al. (1999) considered conversation as "a variety of language deserving particular attention in its own right" (p. 1038). They pointed out that face to face interaction encompasses not only an immediate physical context of time and space but also a large amount of social, cultural and institutional knowledge. Conversation is therefore a unique register in its own kind. Every day conversation is different from written language in different social and regional contexts. Written language in most cultures has its own unique status and legacy that have been kept and preserved due to specific historical engraved rules and conventions for thousands of years. Yet, conversation has been recently recorded, analyzed and discussed. Only through conversational analysis we begin to unveil the varied communicative practices involved in discourse construction of everyday talk.

CA is traditionally related to ethnomethodology. It aims at scrutinizing the communicative conventions and practices that native speakers adopt to use the language to interact socially with other humans in natural contexts rather than hypothesizing ways as to how speakers ought to use the language. It focuses on talk-in interaction (verbal/non-verbal). It is becoming widely an accepted approach in L2 acquisition. Linguistic and educational studies provided the literature with some pedagogical perspectives of how conversational analysis could be implemented in the field of language teaching and learning (e.g., Brouwer \& Wagner, 2004; Kasper, 2006; Markee, 2004; Riggenbach, 1999; Olshtain \& Celce-Murcia, 2001; Seedhouse, 2005).

Thus, as Ortega (2005, p. 323) commented, CA has become another "strong alternative theoretical perspective for SLA". Zuengler \& Miller (2006) added that socially and interactionally oriented research of CA expands the research scope of mainstream SLA. Gradner (2004) pointed out that "CA proposes an examination of the fine detail of talk, of the underlying structures that members of the social group draw upon to constitute their social world" (p. 267).

It can thus be seen that conversational analysis is fairly addressed and valued in the field of SLA. Many researchers optimistically sees CA as an adequate tool for providing information of conversational practices governing the way native speakers treat each other's talk (Hellermann, 2008; Seedhouse, 2011; Strong, \& Baron, 2004). Such practices, as the present research suggests, is a necessity in the EFL learning context where structural mechanisms necessary for sustaining conversations such as, turn taking and adjacency pairs, stylistic and linguistic features are neglected or passed by unnoticed. Paying attention to such practices, teachers could have a better vision of how to prepare their students to be successful L2 communicators. Also learners could begin to see how these practices might push them to examine their own beliefs and practices of the target language through a different lens.

\subsection{Principles of $C A$}

The most salient feature of CA can be seen in the way interlocutors build a shared knowledge of understanding through a set of mutual verbal/nonverbal mechanisms. Hutchby \& Wooffitt (1998) claimed that the primary aim of CA is to "discover how participants understand and respond to one another in their turns at talk, with a central focus being on how sequences of actions are generated" (p. 14). Wong \& Waring (2010) argued that, one of CA's fundamental concerns is: what do people do in order to have conversation? What are the commonsense practices by which we engage in conversation? (p. 4).

A decent account of CA basic principles was proposed by (Seedhouse, 2005) which are as follows:

1) There is order at all points in interaction: Talk in interaction is systematically organized, deeply ordered and methodic.

2) Contributions to interaction are context-shaped and context-renewing

3) CA has a detailed transcription system, and a highly empirical orientation. 
4) Analysis is bottom-up and data driven. (pp. 166-167)

Wong \& Waring (2010) presented CA principles in three broad categories:

1) Collecting data which requires naturally occurring data taken from the actual occurrences of talk not from manipulation,

2) Transcribed data using a fine-grained transcription system

3) Analyzed data from an emic perspective which accounts for interlocutors' language in social interaction. (pp. 4-7)

Considering the above criterions, CA can be a powerful tool to propel EFL learners to a greater amount of success in their developmental processes of speaking. For instance, CA can be used to enhance learners' language competencies. For example, following CA's principles and its methodical system of gathering and analyzing data, we can provide EFL learners with the status of participants, the purposes of interactions, and the norms or conventions of interactions. Those factors as pinpointed by (Freeman \& Freeman, 2004) are what constitute sociolinguistic competence and that learners should be introduced to.

\subsection{Organizational Structures of Conversation}

The units of conversational organization were unveiled via CA involving many aspects such as "adjacency pairs", "turn taking", "turn organization", "action formation", "sequencing", "repair", "word/usage selection", "recipient design" and "overall organization of the occasion of interaction" (Schegolff, Koshik, Jacoby, \& Olsher, 2002, pp. 4-5).

Adjacency pair is a typical organizational feature of many formal/informal conversations. It involves in its basic structure sequences which constitute a first part followed by second part and produced by two speakers (Levinson, 1983; Schegloff \& Sacks, 1973; Yule, 1996). Speech acts including greeting, requesting, offering help and complement sequences are classical examples of adjacency pairs. Thus, the utterances contained in the adjacency pair are usually responses to utterances which precede them, such as question/answer or, greeting/greeting, request for information/ refusal, etc. However, as McCarthy (2002) suggested, "adjacency pairs vary from culture to culture, and are affected by social settings, such as role relationships, situation" (p. 121).

Insertion sequences which are considered as one type of adjacency pairs can function as additional parts embedded within another adjacency pairs. Gardner (2004) explained that "insertion sequences often occur as repairs to an actual or potential misunderstanding of the first pair part, to clear up a mishearing or ambiguity or non-comprehension, before doing the second pair part" (p. 274).

Turn taking is yet another level of orderliness in the organization of talk put forth by Sacks, Schegloff, \& Jefferson in (1974). Schegloff (2007) argued that,

One of the most fundamental organizations of the practice for talk-in-interaction is the organization of turn taking. For there to be the possibility of responsiveness-of one participant being able to show that what they are saying and doing is responsive to what another has said and done-one party needs to talk after the other, and, it turns out, they have to talk singly. (p. 1)

Turn taking in its smooth pattern refers to the transition relevance places at which an utterance is complete. Such transitions between speakers can be signaled by syntactic cues, intonation, non-verbal cues such as gestures or eye contact (Sacks et al., 1979). Later studies revealed more complex structures of turn taking and indicated that turn taking is culturally variable and that it differs from one culture to another (Lehtonen \& Sajavaara, 1985; Tannen, 1984). Lehtonen \& Sajavaara (1985) noted that longer pauses were normal between Finnish speakers whereas American speakers tended to interrupt longer pauses before turns indicating that they were not interested to continue the conversation. Lehtonen \& Sajavaara (1985, p. 270) attributed such phenomenon to 'Scandinavians' cultural preference for speaking only when they had something to say as opposed to the talkativeness style which was a character of the majority of American speakers".

Another pattern of turn-taking is overlapping speech which was considered by (Sacks et al., 1979) as minimal and normally located around transition relevance place. Gardner et al. (2009) suggested that gaps and over laps are not a part of smooth transitions and may indicate signs of trouble in communication. Tannen (1982) in her work revealed that there is overlapping practices more than turn taking strategy, marked shifts in pitch and amplitude and preference for storytelling. It is also the case for the present study in the analysis of the TV excerpt where speakers exhibit informality and high involvement via many instances of overlapping, fast rate of speech, high pitch cut off sounds, and interruptions. 
Another feature that contributes to the organization of conversation is the use of minimal responses which are defined by Fishman (1983) as monosyllabic utterances used by speakers when they take their turn such as, huh, yeah, umm. These words are considered as conversational supports provided by listeners, signaling their involvement in the interaction. However, Fishman (1983) noticed that "while women use minimal responses as support work - to allow for the conversation to continue - to let the speaker know that she is listening, men usually use such minimal responses to show lack of interest" (p. 95).

The analysis of such speech behavior of native speakers provides valuable information of what rules and assumptions they bear in mind when involved in discourse interaction. As Young (2002) put it, "we agree on a wide range of communicative conventions; without these conventions, it would be impossible to understand what each of us means when we say something" (p. 1). Tannen (1990) asserted that conversational styles like, tone of voice, speeding up and slowing down, pausing, getting louder and softer are guiding what we say and how we say it.

When such information made available to EFL teachers and students, there would be a clearer picture of how the target language culture operates and how the native speakers establish meaning and sustain it. EFL learners would, therefore, be more able to deal with communicative endeavors while cooperating with other speakers to understand, establish and exchange meaning.

\subsection{Interactional Competence}

The concept of interactional competence has recently been of great interest to many SLA research, particularly those of communicative focus in L2 acquisition. Wong \& Waring (2010) defined interactional competence as "the ability to use verbal and non-verbal resources for participating in exchanges" (p. 7). Oksaar (1990) defined interactional competency as;

The ability of a person, in interactional situations to carry out and interpret verbal, paralinguistic, non-verbal and extra-verbal communicative actions in two roles, that of the speaker and that of the hearer, according to the sociocultural and psychological rules of the group. (p. 530)

Recently, Young (2008), adding identity and context, provides a more comprehensive definition of interactional competence which is,

A relationship between the participants' employment of linguistic and interactional resources and the contexts in which they are employed; the resources that interactional competence highlights are those of identity, language and interaction.(p. 100)

Markee (2008) viewed interactional competence in terms of three elements: 1) a formal system, including pronunciation, vocabulary, grammar, 2) semiotic system, including turn-taking, repair, sequence organization, and 3) paralinguistic features.

The body of L2 research now is more prone to advocate the use of conversation analysis in the field of teaching and learning, however, under the construct of interactional competence. Many SLA studies indicated that since CA focuses on talk-in-interaction, the focus of CA should be more concerned with elements of interactional competence. They view learning a second language as primarily an interactional process that is socially and culturally constructed by L2 learners (Celce-Murcia, 2007; Gardner et al., 2009; Walsh, 2012; Wong \& Waring, 2010). Wong \& Waring (2010), for example, stated that,

Conversation analysis offers a wealth of knowledge that can make our understanding of interactional competence more specific, more systematic, and more pedagogically sound. Conversation analysis delivers the stuff that interactional competence is made of, i.e., interactional practices. (p. 8)

CA also embraces sociolinguistic, pragmatic and grammatical competencies. Kasper (2006) pointed out that "interactional competencies qualitatively expand SLA's traditional learning object of grammatical and even pragmatic competence" (p. 87). Celce-Murcia (2007) added the construct of interactional competence to the model of communicative competence arguing that interactional competence entails the ability to successfully use syntactic, semantic, and lexical resources when interacting. Further, Young (2011) proposed four components of what constitute the construct of IC.

1). Verbal/non-verbal spoken interaction

2). the pragmatics of interaction

3). the shared mental context through the collaboration of all interactional partners.

4). the context of an interaction which includes the social, institutional, political, and historical circumstances 
that extend beyond the horizon of a single interaction.

Thus, the concept of interactional competence do not only entail the units of conversational organization, such as, turn taking and adjacency pairs but also how to initiate, manage and negotiate for meaning in a conversation. It also includes body language, eye contact and proximity.

Most of these practices of interactional competence of conversations are still unknown or unexploited in the Saudi EFL classroom. In such context, the interplay between teachers and their students is mechanical rather than communicative. This learning context usually imposes a reciprocal exchange of a question and answer relationship. Teachers are dominating the scene and some never allow any contributions from the side of the students who are compliant with this submissive EFL learning environment. Being a teacher in the same EFL context, I should also confess that some teachers and students seem to like such passive learning atmosphere where fewer responsibilities are to be demanded on both teachers and learners.

What follows is a detailed analysis of an excerpt from a TV talk show. The analysis documents different linguistic, stylistic, situational features along with other interactional practices involved in native speakers' everyday talk. This analysis is meant to draw EFL teachers' attention to the features and practices that characterize everyday language in use which are inaccessible when learning a language only from textbooks. As Wong \& Waring (2010, p. 55) put it "CA findings can help to invigorate teachers' interest in achieving a nuanced sense of language and social interaction".

\section{Applying CA to a Seven-Minute Excerpt of a TV Talk Show}

This analysis explores various interactional practices used by the speakers to establish their rapport and sustain the topic of discussion. Following Young (2011) and many other SLA researchers on what constitute interactional competence; the construct of "interactional practices" for this study will refer to all verbal and organizational mechanisms of interactional competence used by the speakers in the TV talk excerpt. Hence, the analysis has three main parts. The first part discusses characteristics of the conversation such as, situational characteristics, lexical choices, linguistic and pragmatic features. The following part discusses conversational organization used by the speakers. The last part sheds light on the occurrences and functions of linguistic devices such as cooperative repetition, backchannels, machine gun questions and its impact on the flow of conversations. See (Appendix A) for a detailed transcription of the TV talk show excerpt.

\subsection{Part1: Characteristics of the Conversation}

\subsubsection{Situational Features}

The seven-minute excerpt is taken from a conversation that takes place in a talk show called "Hot Tickets". There are two speakers who take turns in this conversation, Joyce Kulhawik and Leonard Maltin. The addressees are those who watch the show. The physical setting is a studio that broadcasts this show on channel 10 . The talk show also displays some excerpts from the movie "Hollywood Homicide", so that the addressors could analyze it for the audience. This conversation is taken from the "talk show media register" which is different from the "news media register" in terms of its formality, purpose, conversational styles and the degree of involvement. The purpose of the talk is then to analyze the movie "Hollywood Homicide" and that involves a lot of disputes between the two participants of the conversation about the plot of the movie and its characters, particularly, Harison Ford's character.

\subsubsection{Lexical Choice}

The participants' lexical choice is simple and does contribute to the overall theme of the conversation. For example, the use of words such as, crime plot, play, role, scene, can significantly draw the audience's attention to the type of topic under discussion. There is also distinguished use of informal words and phrases, such as, "buddy" and "see little". There is also a high frequency use of adjectives and nouns that contribute to the overall description and analysis of the movie (e.g., hot young partner/ popular rap / touchy feeling / estate agent, etc.)

However, there are not instances for the use of particular technical terms or words that distinguish this register from other registers. Rather, the speakers tend to interact and converse in a similar way to speakers engaged in a normal conversation. That is to say, that this register, in fact, bears many features that are to be found in a conversation register except for the physical setting and the type of considerations associated with such setting.

\subsubsection{Linguistic Features}

From a linguistic and grammatical point of view, there are many features that add to the informality of this conversation. For example, the two speakers tend to use morphological reductions, such as, "should've", "loose'm", and "gonna". They also use many lengthy grammatical structures such as subordinate and coordinate 
clauses. In such setting, each speaker is trying to prove his point of view, though syntactically, the order of the words is not highly organized. For example, the utterances in "like how he was kin- of loose'm funny which we haven't seen them being in a role", lack such syntactic organization and constitute an important conversational feature that is, "the add-on strategy". There are also instances of the use of interjections, such as, "oh, yeah, I see", discourse markers, such as, "well", and vocatives, such as "buddy". There are also instances for dysfluencies such as, "see. I can't disagree with you. ah, well, ah, lis- I didn't like that opening scene". All the above features are characteristics of informal conversations and usually convey a casual tone of the speakers.

\subsubsection{Pragmatic Features}

Although, there are many features of high involvement style such as, overlapping and latching, there is also a noticeable flow of the conversation. For example, from the pragmatic point of view, there is a noticeable conversational flow in turn taking, as the two speakers are chatting about a general topic which indicates that they share a lot of interests, experiences, and information about the events of the movie. From the linguistic point of view, there is considerable pacing which includes elements like, faster rate of speech, high pitch, avoiding lengthy pauses, and breathy voice.

However, there are not instances of negative politeness or any attempt to minimize imposition. The two speakers are highly engaged in the topic of the show and try to prove their argumentative points of view rather than taking care of negative politeness rules as not to impose particular thoughts on each other. However, there are many instances of positive politeness as speakers of the conversation show the desire to be liked and to be approved of, such as "yeah", and "that's right". There also instances for backchannels and non-clausal units such as, "mmh" which indicates the participatory listenership between the two speakers and that are confined to positive politeness.

Applying CA to this talk-in-interaction reveals the abundant use of informal language, discourse markers, fillers and other communication strategies that EFL learners are not acquainted with. EFL learners have a limited output to produce which is also restricted to the language they read in their textbooks or hear from their professors. This inadequate and inactive L2 learning may be what causes Saudi learners to remain passive in class.

Although they are learning many new words in every class, their oral output is unbelievably circling around few words and sentences that they keep repeating and only whenever they are forced to say something. One may say EFL learners simply lack the context for using such lexis. Then, why not introducing them to common everyday linguistic features they are prone to encounter when watching a movie or TV talk show, listening to songs, or texting in social media, etc. Thus, EFL learners can benefit from being introduced to such communicative practices at least for the sake of listening and understanding and writing if not for speaking.

\subsection{Part 2: Practices of Conversational Organization}

The conversation is highly informal and the two speakers cooperate together to convey the theme of the show to the audience in such a manner that guarantees high involvement on the part of the speakers and presumably great interest on the part of the audience. The conversation is also featured by organizational practices, such as, the adjacency pairs though not as clear and organized as, for example, in a formal setting. This is because this informal setting includes many instances of overlapping, and latching, repetition of utterances. The use of overlapping and latching signals the use of rapid speech and high pitch cut off sounds, interruptions, which in turn, signal the casual tone of the conversation and the closeness of the speakers.

There is also a bonding through high-involvement style because of the successful latching and overlapping where speakers encourage each other to speak. This is explainable by the fact, as Tannen (1984) suggested that speakers know each other for a significant length of time. The two speakers also volunteer to add information or ask questions that give matter for further talk. They repeat each other's utterances too. For example,

B: And it is on Hollywood. 7

A:

LIt's on Hollywood. that's were...

The two speakers also show persistence on the same topic. This is apparent from the repetition of utterances, hesitance signals, overlapping, latching, and the use of machine-gun questions as in "what was percolating".

The way organizational practices are used by speakers, revealed via applying CA, is what constitute informality and high involvement of the speakers in the above excerpt. Wouldn't these vivid stylistic informalities be of more interest to the EFL Saudi context? A context where learners are fed up with the formality hammering their 
brains while learning English? Isn't it a priority for language educators to seek what suits their learners' current needs who are living in this globally connected world rather than what suits outdated institutional needs? This paper is, therefore, trying to find its way to advocate the use of CA as a means to aid EFL teachers in their speaking classes in particular. There would be no conflict, indeed, if we can go a little beyond the traditional restrains for better enhancement of our learners' communicative and interactional competencies.

\subsection{Part 3: Occurrences and Functions of Main Linguistic Devices}

Table 1. The total number of occurrences of linguistic devices

\begin{tabular}{llll}
\hline Features & Total & Joyce & Leonard \\
\hline Interruption & 24 & 10 & 14 \\
Back channel & 7 & 4 & 3 \\
Cooperative repetition & 1 & 1 & 0 \\
Machine gun & 6 & 1 & 5 \\
Latching & 4 & 1 & 3 \\
\hline Turn length & & About 28.3 seconds/turn & About 11.5/turn \\
\hline
\end{tabular}

The table above shows that in this conversation Leonard interrupted Joyce more than Joyce did. Leonard interrupted 10 times out of 24 times. This might come from the fact that Joy talked more often and longer than Leonard did. Therefore, Leonard tried to take the floor by interrupting Joyce a lot. Joyce gave more minimal responses or back channeling more than Leonard.

Table 2. Functions of main linguistic devices

\begin{tabular}{|c|c|c|c|c|c|c|c|c|}
\hline \multirow{2}{*}{$\begin{array}{l}\begin{array}{l}\text { Function of } \\
\text { interruptions }\end{array} \\
\text { Speakers }\end{array}$} & \multicolumn{3}{|c|}{ Encouragement/Support } & \multicolumn{4}{|l|}{ Take the floor } & \multirow[t]{4}{*}{ Total } \\
\hline & \multirow{2}{*}{\multicolumn{3}{|c|}{$\begin{array}{l}\text { Joyce }=4 \\
\text { Leonard } 9\end{array}$}} & \multirow{2}{*}{\multicolumn{4}{|c|}{$\begin{array}{l}\text { Joyce }=6 \\
\text { Leonard }=3\end{array}$}} & \\
\hline & & & & & & & & \\
\hline & $\begin{array}{l}\text { Back } \\
\text { channel }\end{array}$ & $\begin{array}{l}\text { Machine } \\
\text { questions }\end{array}$ & Latching & $\begin{array}{l}\text { Cooperative } \\
\text { repetition }\end{array}$ & Latching & Overlap & $\begin{array}{l}\text { Machine gun } \\
\text { questions }\end{array}$ & \\
\hline Joyce & 4 & 0 & 0 & 1 & 2 & 2 & 1 & 10 \\
\hline Leonard & 3 & 5 & 1 & 0 & 1 & 1 & 1 & $\begin{array}{l}12 \\
(+2 \text { unclear } \\
\text { utterances })\end{array}$ \\
\hline
\end{tabular}

According to Table 2, even though Leonard interrupted Joyce more than Joyce did, Leonard mostly used his interruptions to give support to Joyce to keep talking. Joyce, however, used the interruption mostly to take the floor. Most of the machine gun questions Leonard used are to give encouragement and support (5 out of 6).

The use of the above linguistic devices enhances conversation flow and sustains high involvement and rapport among speakers taking into account that the two speakers shared lots of interest, knowledge and experiences. They also reflect the ways that the speakers' used inferences to proceed through their interaction and to meet the demands of the talking in such an interview.

To sum up, the situational features, such as, the physical setting and the content of the topic serve the addressees, to a great extent, to convey the main intended purpose which is to analyze the "New York Homicide" movie. Similarly, the linguistic features, such as, morphological reduction, lack of syntactic organization, use of interjections, discourse markers, the use of informal vocatives and the use of informal words and phrases contribute to the informality of the setting and the causal argumentative tone of the conversation. The high involvement style, featured by overlapping, latching, high pitch, and fast turn taking serves another purpose which is to add spontaneity and vividness to the conversation.

\section{Implications for the EFL Context}

Many EFL teachers at Jazan University are disappointed at their students' passiveness. They are also dissatisfied with the administration's inflexibility with regard to having more freedom to suit their classes according to their students' needs and the current practices in SLA. Teachers are actually obliged to follow the prescribed syllabus distribution particularly in the preparatory year and use particular textbooks approved by the administration. In fact, a few proposals with regard to the development of students' oral skills have been discussed with the 
administration. However, those proposals lacked the teaching rationale to substitute or support old teaching practices. This could be one of the reasons why the administration persists on using the old prescriptive teaching methods which are also a common tendency in many other EFL contexts (Li, 1998; Littlewood, 2007; Nunan, 2003).

The above model for CA analysis of the TV excerpt is to be submitted to the administration of Jazan University. The teaching goal is to allow teachers to experience the implementation of the conversational practices analyzed in the above CA model. The learning goal is to engage EFL learners in analyzing excerpts of authentic talk to;

(1) enhance their oral proficiency

(2) educate and empower them with features of everyday talk,

(3) raise their cognitive and meta-cognitive skills,

(4) develop awareness and tolerance of breakdowns in communication and

(5) learn strategies to overcome and compensate for any failure in communication.

The model will also include the following pedagogical recommendations for the use of CA in the Saudi EFL context.

1) Teachers should be trained on analyzing the fine details of every day talk.

2) EFL learners should be acquainted with the interactional practices mentioned above with more focus on organizational structures of conversation such as self-repair in communication breakdowns, adjacency pairs, initiating a turn, overlapping others' speech, or continuing a turn. ESL textbooks do not usually discuss such practices.

3) Written transcribed texts of authentic excerpts could be used as a primary guide for learners

4) Authentic excerpts are preferably be analyzed by learners with their teachers' assistance.

5) Authentic audio or video excerpts are only to be selected as teaching/ learning materials. As Riggenbach (1999, p. 5) put it, "authenticity of text is essential for insight into actual language use. Rather than created examples of sentences and structures by introspective methods, most language researchers interested in discourse use "real data" - talk, audiotaped or videotaped, or writing".

6) Authentic excerpts should be analyzed and transcribed in terms of turn sequences rather than single sentences.

7) EFL learners can analyze the ways turns are constructed to determine the possible completion of turns by interlocutors in order to take the floor.

8) EFL learners need to observe and notice naturally occurring speech within the context of socio-cultural interaction. Learners are therefore not only the receivers of knowledge but also the analyzers and researchers for knowledge.

9) EFL learners need to recognize the ways interlocutors construct their discourse and understand other interactants.

10) EFL learners should be able to recognize the ways in which speakers know when and how to begin or end talk which is a challenge for many L2 learners.

11) EFL learners should understand the orderliness of the structures of compliments, announcements, invitations, complaints, etc.

12) EFL learners can move then from organization sequencing of talk to larger sequential processes of topic development and topic management, such as initiating and shifting topics.

13) They can use interactional resources of turn taking and adjacency pairs to secure or assign a turn and thus be able to work out the type of response that is being produced.

14) From a CA standpoint, writing utterances as exactly they are heard by native speakers would help EFL learners have access to the way native speaker use the language in everyday talk. EFL learners may read "how are you" and use it in speech but may never imagine that such expressions might rather be pronounced as "hawarya".

\section{Conclusion}

Several CA research, using CA-informed pedagogical approach, adopted the analysis of in-class conversations between student-student and teacher-student which are instructed via the use of interactional skills. They 
describe verbal exchanges that occur in the L2 classroom. This study, however, proposes training learners while introduced to interactional skills through listening to authentic real life spoken discourse. It advocates the use of CA as a learning talk analysis to teach naturally occurring talk and enhance EFL learners' oral proficiency. It suggests that before examining the internalization of particular pragmatic and interactional functions in learners' discourse, it might be wiser to raise learners' awareness of the presence of such functions in the speech of native speakers in real life contexts. Learners would rather value learning a second language through observed features of natural behaviors rather than specified parameters of teacher and learners talk in class analysis. As Garner (2012) pointed out, "Moments of learning" may be unlocatable; but what one can locate is orientation to learning: attempts to do something new that one has not done before; attempts revealed by linguistic and non-linguistic behaviors) (p. 237).

In conclusion, CA can induce EFL learners to abandon their default perception of conversation as static scripted texts into a dynamic entity of its own. Yet, applying CA in class to analyze natural talk by native speakers is not an easy task to accomplish in the EFL Saudi setting. It is a novel shift for both teachers and learners from how language is prescribed in textbooks to how it is actually used in native speakers' talk. However, if we need to prepare EFL Saudi students for success in the internationally interconnected world, interactional practices should be essential constituents of EFL speaking curriculum in Saudi Arabia.

\section{References}

Barbieri, F., \& Eckhardt, S. (2007). Applying corpus-based findings to form-focused instruction. Language Teaching Research, 11(3), 319-346. http://dx.doi.org/10.1177/1362168807077563

Biber, D., \& Reppen, R. (2002). What does frequency have to do with grammar teaching? Studies in Second Language Acquisition, 24(2), 199-208. http://dx.doi.org/10.1017/S0272263102002048

Biber, D., Johansson, S., Leech, G., Conrad, S., \& Finegan, E. (1999). Longman grammar of spoken and written English. Harlow, England: Pearson Education.

Brouwer, C., \& Wagner, J. (2004). Developmental issues in second language conversation. Journal of Applied Linguistics, 1(1), 30-47. http://dx.doi.org/10.1558/japl.1.1.29.55873

Celce-Murcia, M. (2007). Rethinking the role of Communicative Competences in language teaching. In E. Alcon Soler \& M. P. SafontJordà (Eds.), Interculturallanguage use and language learning (pp. 41-58). The Netherlands: Springer. http://dx.doi.org/10.1007/978-1-4020-5639-0_3

Fishman, P. (1983). Interaction: the Work Women Do. University of California, Santa Barbara.

Freeman, D. E., \& Freeman, Y. S. (2004). Essential linguistics: What you need to know to teach reading, ESL, spelling, phonics, and grammar. Portsmouth, NH: Heinemann.

Gardner, R. (2004). Conversation Analysis. In A. Davies \& C. Elder (Eds.), The Handbook of Applied Linguistics (pp. 262-284). Oxford: Blackwell. http://dx.doi.org/10.1002/9780470757000.ch10

Gardner, R., \& Wagner, J. (2004). Second language conversations. London: Continuum.

Gardner, R., Fitzgerald, R., \& Mushin, I. (2009). The underlying orderliness in turn-taking: Examples from Australian talk. Australian Journal of Communication, 36(3), 65-90.

Garner, R. (2012). Conversation Analysis and orientation to learning. Journal of Applied Linguistics, 5(3), 229-244. http://dx.doi.org/10.1558/japl.v5i2.229

Gilmore, A. (2004). A comparison of textbook and authentic interactions. ELT Journal, 58(4), 363-371. http://dx.doi.org/10.1093/elt/58.4

Hellermann, J. (2008). Social Actions for Classroom Language Learning. Clevedon: Multilingual Matters.

Hutchby, I., \& Wooffitt, R. (1998). Conversation Analysis. Cambridge: Polity Press.

Kasper, G. (2006). Beyond repair: Conversation analysis as an approach to SLA. AILA Review, 19, 83-99.

Kincheloe, J. (2005). Critical constructivism. New York: Peter Lang Publishing, Inc.

Lehtonen, J., \& Sajavaara, K. (1985). The Silent Finn. In D. Tannen \& M. Saville-Troike (Eds.), Perspectives on Silence (pp. 193-201). Norwood, NJ: Ablex.

Levinson, S. C. (1983). Pragmatics. Cambridge: Cambridge University Press.

Li, D. (1998). It's always more difficult than you plan and imagine: Teachers' perceived difficulties in introducing the communicative approach in South Korea. TESOL Quarterly, 32(4), 677-703. 
http://dx.doi.org/10.2307/3588000

Markee, N. (2004). Zones of interactional transition in ESL classes. Modern Language Journal, 88, 583-596. http://dx.doi.org/10.1111/j.0026-7902.2004.t01-20-.x

Markee, N. (2008). Toward a learning behavior tracking methodology for CA-for-SLA. Applied Linguistics, 29, 404-427. http://dx.doi.org/10.1093/applin/amm052

McCarthy, J. J. (2002). A Thematic Guide to Optimality Theory. Cambridge: Cambridge University Press.

Mesthrie, R., Swann, J., Deumert, A., \& Leap, W. L. (Eds.) (2000). Introducing sociolinguistics. Edinburgh: University Press.

Moreno, J. M., \& Perez, B. C. (2009). Developing conversational competence through language awareness and multimodality: the use of DVDs. ReCALL, 21(3), 283-301. http://dx.doi.org/10.1017/S0958344009990036

Nunan, D. (2003). The impact of English as a global language on educational policies and practices in the Asian-Pacific region. TESOL Quarterly, 37(4), 589-613. http://dx.doi.org/10.2307/3588214

Oksaar, E. (1990). Language contact and culture contact: Towards an integrative approach in second language acquisition. In H. Dechert (Ed.), Current trends in European second language acquisition research (pp. 230-243). Clevedon: Multilingual Matters.

Olshtain, D., \& Celce-Murcia, M. (2001). Discourse analysis and language teaching. In D. Schiffrin, D. Tannen, $\&$ H. E. Hamilton (Eds.), The handbook of discourse analysis (pp. 707-724). London: Blackwell.

Ortega, L. (2005). Methodology, Epistemology, and Ethics in Instructed SLA Research :An Introduction. The Modern Language Journal, 89(3), 317-327. http://dx.doi.org/10.1111/j.1540-4781.2005.00307.x

Riggenbach, H. (1999). Discourse analysis in the language classroom: Vol. 1. The spoken language. Ann Arbor: The University of Michigan Press. http://dx.doi.org/10.3998/mpub.8353

Sacks, H., Schegloff, E., \& Jefferson, G. (1974). A simplest systematics for the organization of turn-taking for conversation. Language, 50, 696-735. http://dx.doi.org/10.1353/lan.1974.0010

Schegloff, E. (2000). Overlapping talk and the organization of turn-taking for conversation. Language in Society, 7, 1-63. http://dx.doi.org/10.1017/s0047404500001019

Schegloff, E. A. (1988). Goffman and the analysis of conversation. In P. Drew \& A. Wootton (Eds.), Erving Goffman: Exploring the interaction order (pp. 89-135). Cambridge: Polity Press.

Schegloff, E. A. (2007). Sequence organization in interaction: A primer in conversation analysis. Cambridge: Cambridge University Press. http://dx.doi.org/10.1017/CBO9780511791208

Schegloff, E. A., \& Sacks, H. (1973). Opening up closings. Semiotica, 7, 289-327. http://dx.doi.org/10.1515/semi.1973.8.4.289

Schegloff, E. A., Koshik, I., Jacoby, S., \& Olsher, D. (2002). Conversation analysis and applied linguistics. Annual Review of Applied Linguistics, 22, 3-31. http://dx.doi.org/10.1017/s0267190502000016

Seedhouse, P. (2005). Conversation analysis and language earning. Language Teaching, 38(4), 165-187. http://dx.doi.org/10.1017/S0261444805003010

Seedhouse, P. (2011). Conversation Analytic Research into Language Teaching and Learning. In E. Hinkel (Ed.), The Handbook of Research in Second Language Teaching and Learning, Volume II (pp. 345-363). New York: Routledge.

Strong, M., \& Baron, W. (2004). An analysis of mentoring conversations with beginning teachers: suggestions and responses. Teaching and Teacher Education, 20, 47-57. http://dx.doi.org/10.1016/j.tate.2003.09.005

Tannen, D. (1982). Oral and literate strategies in spoken and written narratives. Language, 58, 1-12. http://dx.doi.org/10.2307/413530

Tannen, D. (1984). The Pragmatics of Cross-Cultural Communication. Applied Linguistics, 5(3), 189-195. http://dx.doi.org/10.1093/applin/5.3.189

Tannen, D. (1990). You just don't understand: Women and men in conversation. New York: William Morrow.

Walsh, S. (2012). Conceptualizing classroom interactional competence. Novitas-ROYAL (Research on Youth and Language), 6(1), 1-14. Retrieved from http://www.novitasroyal.org/Vol_6_1/Walsh.pdf

Wong, J., \& Waring, H. Z. (2010). Conversation analysis and second language pedagogy: A guide for ESL/EFL 
teachers. New York: Routledge.

Young, F. R. (2008). Language and interaction: An advanced resource book. London, New York: Routledge.

Young, F. R. (2011). Interactional competence in language learning, teaching, and testing. In E. Hinkel (Ed.), Handbook of research in second language teaching and learning (vol. 2, pp. 426-443). London \& New York: Routledge.

Young, R. M. (2002). The Cooperative Contract in Interactive Entertainment. In Socially Intelligent Agents (chapter 28, pp. 229-234). New York: Kluwer Academic Press. http://dx.doi.org/10.1007/0-306-47373-9_28

Yule, G. (1996). Pragmatics. Oxford: Oxford University Press.

Zuengler, J., \& Miller, E. R. (2006). Cognitive and Sociocultural Perspectives: Two Parallel SLA Worlds? TESOL Quarterly, 40(1), 35-58. http://dx.doi.org/10.2307/40264510

\section{Appendix A}

\section{Transcript}

Joyce:...Indiana Jones Harrios Ford's become a movie legend by playing a hero who

likes to work alone, but now he's joined by a hot young partner. Welcome to Hot Ticket. I'm Joyce Kulhawik.

Leonard: I'm Leonard Maltin.and Hollywood homicide four series of things including Pearl Harbor star Josh at charge.we are given about fifteen seconds to decide the character he plays and their actions come.

\section{--------excerpt from the movie---------------}

Leonard: Partner to partner with Ford who doesn't hide his propensity to be paired with a rookie detective.

\section{-------excerpt from the movie-------------}

Leonard: Their investigation as a plotter of a popular rap group brings out the worst to each other. such a partner that extremely reckless driver.

\section{--------excerpt from the movie-}

Joyce: I have an incredibly mixed reaction to this movie. At first $\lceil$..at first I thought it

Leonard: Lmixed in what way?

was just sort of a contrived effort to do what's become a pretty cliched device, that is a mismatch talk $\lceil$ buddy talk..mistaking. One is old, one is young..one is

$$
\text { Leonard: Lmmh }
$$

tough. One is touchy feeling. But these two are also multi tasks taking, so one, Harrison Ford is the real estate agent on the side $\lceil$ and Josh has to decide whether

$$
\text { Leonard: } L \text { yeah }
$$

to be or not to be an actor... and oh, by the way, he has to also also put on a

Leonard: Lha ha (laugh)

Hamlet who tried to put on a play or solve his father murder. It's a lot on this movie play.

Leonard:And it is on Hollywood. 7

Joyce: LIt's on Hollywood. That's included in the title. That ..

where the sources of the joke are too. 


\section{--------excerpt from the movie}

Joyce: the homicide that takes in the back scene..to a Hollywood that is the various roles that these character plays and $\lceil\mathrm{I}$ thought they went too far in that direction

$$
\text { Leonard: Lyeah }
$$

because I start caring about the homicide \lceil

$$
\text { Leonard: Lhow can you care about }
$$

the homicide? $\lceil\ldots$ they threw it

$$
\text { Joyce: L..they can’t }
$$

out of the $\lceil$ window

$$
\text { Joyce: Lha ha (laugh) }
$$

Leonard: They threw the whole story out of the window $\lceil$ they threw their credibility out of Joyce:Lyeah

the window $\lceil$ And just they made it goof.

$$
\text { Joyce:Lyeah }
$$

Leonard: Well, Okay, if it is gonna be goof, make it goof from the beginning:-Г Joyce: $\operatorname{Lmmh}$

Leonard:be consistent.

\section{--------excerpt from the movie-}

Joyce: I don't think their intention was to make a goof. I think it was..

a daring idea $\lceil$ and /?/good part shouldn've come together as I think ultimately

$$
\text { Leonard: Land certain what? }
$$

they did by the end of the film it was really perculating we wa- $\lceil$ we want, I

\section{Leonard: Lwhat was}

perculating?

thought that this is the whole concept of being other things of somehow that linking up.... with the crime plot 7

$$
\text { Joyce: L aha }
$$

Joyce: So this comes together towards the end of the film.7

\section{Leonard: LI think you get it.}

Joyce:See, little $\lceil$ (laugh)

$$
\text { Leonard:L (laugh) I think you've been good. } 7
$$

Joyce: LI like the end of the film better than in the

beginning $\rceil$

Leonard: Lreally? 「

Joyce: $\quad L$ I thought the opening scene did not work. 7

Leonard: $\quad\lfloor$ Oh, Gee. I like the

beginning better than the end because at least at the beginning it was what it was.. the cop

buddy moved with the sense of humor. 
Joyce: Another problem I had, Harison Ford's performance. I thought he would be the totally miscast here or he was..He gave a very bad performance ..the close

Leonard: $L$ Oh I like.

scene with the cheese burger when he said.. this is not what I ordered $\lceil$ this

$$
\text { Leonard: } L / ? /
$$

is not ketchup. this is whatever it was. ...it was heavy.everything.the movie came

$$
\text { Leonard: L /?/ }
$$

to a dead stop every time..he.tried to do one of these \lceil

Leonard: Loh, see.I can’t disagree with

you.ah, well, ah, lis-「 I

Joyce: Lwell

didn't like that opening

scene. I didn't like the

introductoryscene..but I

like how he was kin- of

loose'm.funny.which we haven't seen them being in

a long time $\rceil$

Joyce: LI never thought

he was a loose.

Joyce: so I was thought he's still heavy and glum..and of the scenes with BulinaMoven always, who is this guy? When did he take her off? They didn't she seem.....sick of being..troted again as a sex symbol in every single movie we need a sexism call Lina.

\section{-music}

Leonard:I'm not happy in analyzing it, so I'm unhappy to sit through it for two hours

and..and see

the wok of how these people go down the drain.

Joyce: Oh, I like it better than you did .and I appreciate the effort but it did not work..I

vote: not

(showing a NOT card.)

Leonard: And as the resident of Hollywood I am emphatically vote: not. (showing a NOT card.)

\section{Copyrights}

Copyright for this article is retained by the author(s), with first publication rights granted to the journal.

This is an open-access article distributed under the terms and conditions of the Creative Commons Attribution license (http://creativecommons.org/licenses/by/4.0/). 